\title{
Spread of Lymphoma
}

National Cancer Institute

\section{Source}

National Cancer Institute. Spread of Lymphoma. NCI Thesaurus. Code C153404.

A finding indicating the spread of a lymphoma from a nodal or extranodal primary site. 